\title{
Amazing new alkaloid skeletons from the marine sponge Reniera sarai
}

\author{
Guido Cimino, Raffaella Puliti, Gennaro Scognamiglio, \\ Aldo Spinella, Enrico Trivellone \\ Istituto per la Chimica di Molecole di Interesse Biologico del \\ C.N.R. - Via Toiano n. 6, 80072 Arco Felice, Napoli, Italy \\ Carlo A. Mattia and Lelio Mazzarella \\ Dipartimento di Chimica, Università, \\ Via Mezzocannone n. 4, 80134 Napoli, Italy
}

\begin{abstract}
Reniera sarai possesses two homologous series of alkaloids, sarains $\overline{1-3}$ and sarains $A-C$, along with some related minor metabolites which include isosarain-1 (1). We now report the complete structural elucidation of 1 , which supports and further clarifies the previously only partially characterized structures of sarains 1-3. X-ray structure of an acetate derivative of sarain-A has discovered an amazing new macrocyclic alkaloid skeleton. All the sarains have been characterized by an extensive use of 2D NMR methods.
\end{abstract}

\section{INTRODUCTION}

The sponge Reniera sarai (order Haposclerida) is widely present in the Bay of Naples. Its metabolic pattern is heavily characterized by a series of nitroge.nous metabolites, named sarains, belonging to new classes of alkaloids and ex-hibiting interesting chemical and biological properties (ref. 1). In spite of our great interest to characterize these molecules, for a long time their structural elucidation failed. In fact, the difficulty in obtaining single pure compounds and the complex and rarely reproduceable NMR spectra make the structural elucidation of sarains exceptionally challenging.

Our research on $\underline{R}$. sarai started in 1970 but only recently we have obtained the first conclusive results (ref. 2) which led to the partial characterization of three new alkaloids, sarains 1-3. All the suggested structures, possess a trans-fused quinolizidine system jointed to an unsaturated piperidine ring. The two heterocyclic systems are further linked by two alkyl chains, undetermined in the relative length. Now, the full characterization (ref. 3) of isosarain-1 (1), a minor component of $R$. sarai, offers further structural elucidation to this new class of alkaloids. The very abundant. UV absorbing fraction of the sponge likewise resulted to be a mixture of three homologs, sarains $\mathrm{A}-\mathrm{C}$. The structural peculiarities of sarains $\mathrm{A}-\mathrm{C}$ are remarkably different from those of sarains 1-3. However, all the sarains should have a related bio.. genetic origin which could be common to many macrocyclic alkaloids recently reported (refs $4,5,6,7,8$ ) from sponges belonging to the closely related orders Nepheliospongida and Haposclerida.

\section{ISOLATION OF SARAINS}

The n-butanol soluble fraction (6\% of the dry sponge) from the defatted aceto-ne extract of the sponge was fractionized according to the described procedure (ref. 2), first by short overloaded silica gel columns and then submitting the enriched fractions to a series of repetitive chromatographic steps on Jobin-Yvon Miniprep LC instrument. This procedure afforded the three previously described sarains along with a new compound slightly less polar of sarain-1, isosarain-1 (1), and three UV absorbing compounds named in order of increasing molecular weight, sarain-A, sarain-B and sarain-C. After every chromatographic step the recovered fractions were dissolved in chloroform and washed with water to remove all traces of salts. 


\section{STRUCTURE OF ISOSARAIN-1}

Isosarain-1 displayed a mass spectrum almost identical to that of sarain-1 (ref. 2) characterized by the same parent. peak at $\mathrm{m} / \mathrm{z} 466\left(\mathrm{C}_{31} \mathrm{H}_{50 \mathrm{~N}} \mathrm{O}\right.$ ) and the same prominent fragment at $\mathrm{m} / \mathrm{z} 327\left(\mathrm{M}^{+}-\mathrm{C}_{10} \mathrm{H}_{19}\right)$. A $500 \mathrm{MHz} \mathrm{NMR}$ study of 1 , with an extensive use of $2 \mathrm{D}$ shift correlated methods, allowed to individualize all the connectivities of the partial structures A-D. Many NMR assignments were confirmed by traditional mono-dimensional decoupling experiments.<smiles>CC1CCN2CCC(=O)C(C)C2C1C</smiles>

A<smiles>CCN1CC(C)=CC(C)C1</smiles>

B

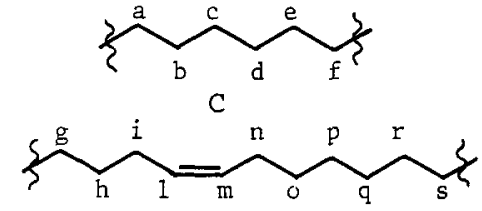

D

The relative stereochemistry at the chiral centres $\mathrm{C} 9, \mathrm{C} 10, \mathrm{C} 1$ and $\mathrm{C} 2$ of the partial structure $A$ was ascertained on the basis of the following evidence: the ${ }^{1} \mathrm{H}-\mathrm{NMR}$ chemical shift of $\mathrm{H}-10$ ( $\delta$ 2.08) suggested a trans-fused quinolizidine junction (ref. 9) which was confirmed by the presence of the typical BohIman bands (ref. 10) in the IR spectrum; the coupling pattern of H-10 (dd; $\mathrm{J}_{1}, 109.2 \mathrm{~Hz} ; \mathrm{J}_{9}, 102 \mathrm{~Hz}$ ) was consistent with axial and equatorial orientations of the substituents at $C-9$ and $C-1$, respectively; the $C-2$ substituent was equatorially oriented on the basis of the $13 \mathrm{C}-\mathrm{NMR}$ resonance value of $\mathrm{C}-4$ $(\delta 53.42$ ) not influenced by $\gamma$ shielding effects. The partial structures $A-D$ were combined placing $C$ between $C 9$ and $C 5^{\prime}$ and $D$ between $C 1$ and $N 1$ 'on the basis of unequivocal NMR evidence. The H2-H3'coupling was not observed in the COSY spectrum. However, at this point the only proposable structure is that depicted in formula 1 characterized by a C2-C3ilinkage. This assignment was confirmed by the obsêrvation that 1 in deuterochloroform solution is slightly transformed in the compound 2 , characterized by a trisubstituted pyridinium ring linked to $\mathrm{C}-2$ ( $\left.{ }_{\mathrm{H}-\mathrm{N}-\mathrm{N} R,} \mathrm{H}-2, \delta 2.98\right)$.
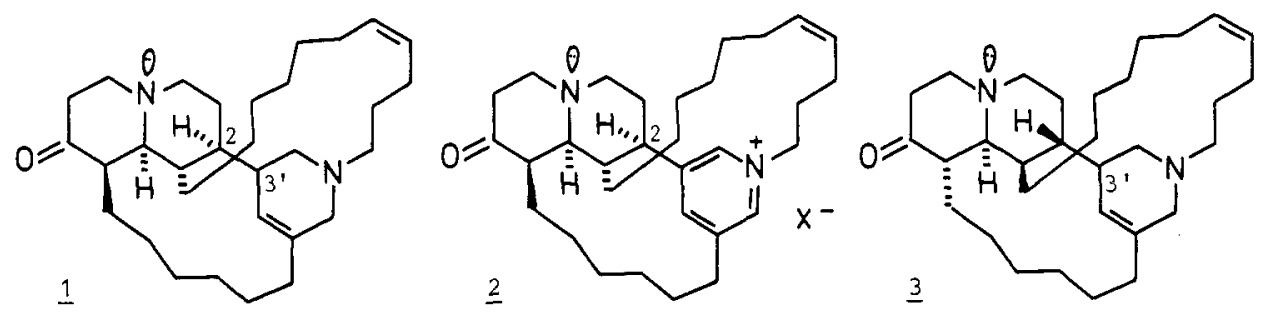

The analogy of the spectral data of 1 with those of sarain-1 (3) suggested that both the metabolites have to possess the same alkyl chains and differ only for the relative stereochemistry at the chiral centres $\mathrm{C}-1, \mathrm{C}-2, \mathrm{C}-9$ and perhaps $\mathrm{C}-3^{\prime}$. Analogously, sarain-2 and sarain-3 differ from sarain-1 (3) only for the structural peculiarities of the longest alkyl chain, $\mathrm{C}_{10} \mathrm{H}_{20}$ in sarain-2 and $\mathrm{C}_{12} \mathrm{H}_{22}$ in sarain-3 with undetermined position of the double bond.

\section{SARAINS A-C}

Sarains-A, B and C, single t.l.c. UV absorbing spot (chloroform:methanol 9:1,

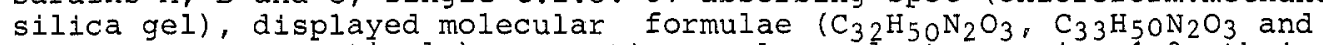
$\mathrm{C}_{3} \mathrm{H}_{52} \mathrm{~N}_{2} \mathrm{O}_{3}$, respectively) suggesting, analogously to sarains $1-3$, their belonging to a homologous series. This was confirmed by some common spectral data: $I R \cong 1650 \mathrm{~cm}^{-1} ; \mathrm{UV} \simeq 238 \mathrm{m \mu} ; \mathrm{MS}$, loss of the same fragment $\mathrm{C}_{14} \mathrm{H}_{22} \mathrm{NO}_{3}$. The com.plex NMR spectra were seldom reproduceable being strongly influenced by traces of salts or acids and, also, by the concentration of the sample. However, working on selected hermetically closed samples, we have been able to submit all the sarains to an exhausting NMR analysis. It probably would have been unsuccessful without the luck of obtaining a crystalline acetate derivative of sarain-A (4) suitable for a resolutive diffractometric study. The single crystal X-ray analysis ( $\mathrm{fig} .1$ ) discovered an incredible structure characterized by a central tetracyclic cage in the middle of two cyclic alkyl chains. Surprisingly, a charged pseudobase moiety is present in the central cage structure; probably it is stabilized by the strong hydrogen bond (2.567 A) between the hydroxyl group and the acetate anion. 


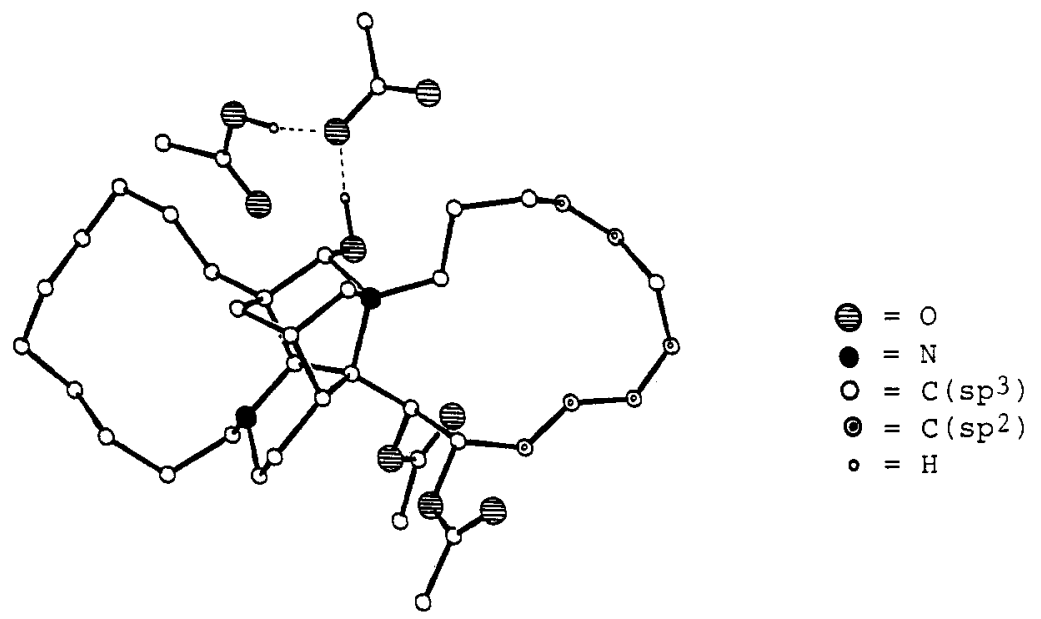

Fig. 1 - Perspective drawing of the acetate derivative of sarain-A (only hydroxylic hydrogens are reported)

The NMR spectra of the crystalline compounds were uninterpretable and strongly influenced by the temperature, by the acidity and by the concentration of the solution.

Sarain-A was recovered unmodified after methanolysis of the acetate. The analysis of the NMR spectra led to the assignment of almost all the resonances, however the signals attributable to the methine group $\mathrm{CH}-2$ were absent. In fact, no signals were recorded in the ${ }^{13} \mathrm{C}-\mathrm{NMR} \delta 110-90$ region and in $1_{\mathrm{H}-\mathrm{NMR}}$ $\delta$ 5.5-4.5 region. However, after addition of equimolecolar amounts of deutero-acetic acid to the deuterochloroform solution of sarain-A, the ${ }_{1} H-N M R$ spectrum was characterized by a new signal at $\delta 4.95$ correlated with a carbon resonating at $\delta 96.6$, as expected for the methine group between two heteroatoms. Probably in deuterochloroform solution sarain-A either displays a "zwitterion" structure or exhibits a strong polarization between the $\mathrm{N}$ and $\mathrm{O}$ atoms, which evolves in the presence of acetic acid to 5 . Bearing in mind the anomalous IR absorption at $1650 \mathrm{~cm}^{-1}$ we prefer this latter hypothesis which could be due to a strong proximity interaction between an aldehyde group and a tertiary amine moiety, remembering the transannular effect described by Leonard et al. (ref. 11) on cyclic 8-aminoketones.

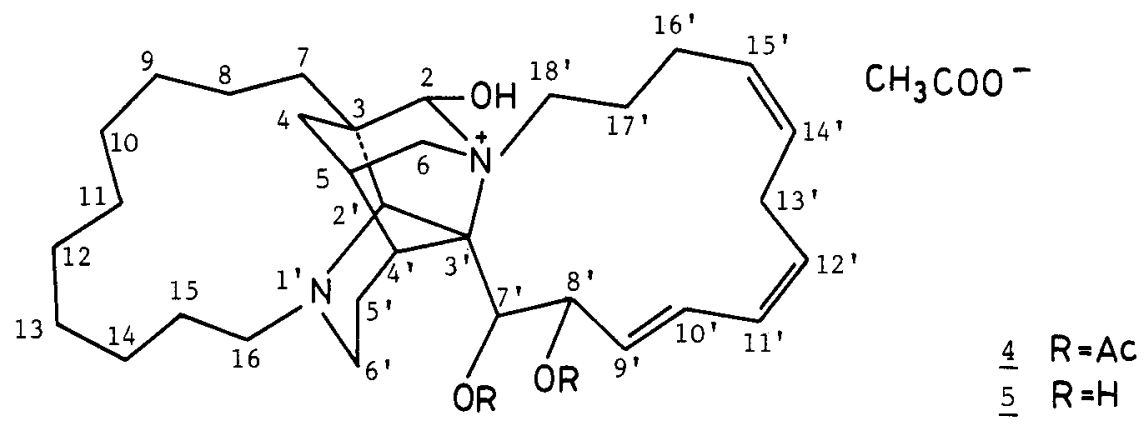

These structural peculiarities can explain the ability exhibited by sarains to link inorganic salts and the strong $\mathrm{pH}$ dependence of their NMR spectra. Analogously to sarains 1-3, sarain-B differs from sarain-A for the presence of an additional carbon atom and of a double bond in the alkyl chain between $\mathrm{N}^{\prime}$ ' and $\mathrm{C} 3$. Whereas sarain-C, in turn, is the superior homolog of sarain-B.

Apparently, there is a great structural difference between the two series of sarains. However, we would try to suggest a common biogenetic origin which derives from the observation that, breaking the 9-10 and 2-3' carbon linkages of 1 and the $1-3^{\prime}, 5,4^{\prime}$ and $3,2^{\prime}$ carbon linkages of 5 , we obtain two macrocyclic skeletons which formally could be obtained by coupling of two 3-alkylpiperidine units. This biogenetic hypothesis could link in an unique scheme Qther macrocyclic alkaloids found in marine sponges, petrosins (ref. 4, 5), 
xestospongins (ref. 6), halitoxins (ref. 12) and, also, it is supported by the recent finding (ref. 13) of two 3-alkyne pyridine derivatives, niphatyne $A$ and $B$, from a Niphates sponge.

We retain that even though only recently (ref. 14) macrocyclic alkaloids have been found in sponges, they could be widely present in sponges of the orders Haposclerida and Nepheliospongida, but their structural complexity has until now prevented any extensive study. However they deserve great attention because almost all these compounds exhibited interesting biological and chemical properties.

Sarains are moderately toxic to mice, toxic to Macrosiphum euphorbiae aphid and to Tetranychus urticae mite, highly toxic in the brine shrimps bioassay with Artemia salina and, furthermore, they are efficient phase transfer catalysts (ref. 2), favouring the displacement in organic solvents of chloride from benzylchloride by acetate ion with a yield comparable to that obtained using 18crown-6 as catalyst (ref. 15).

\section{Acknowledgements}

The authors express their gratitute to Dr. V. Caprioli for the miticide and insecticide bioassays, Dr. A. De Giulio for the brine shrimp test, Dr. S. De Stefano, Prof. I. Minale and, in particular, Prof. G. Sodano for their valuable contributions given to this problem in different times.Our thanks also go to prof. D. Daloze and Prof. R. H. Thomson for the helpful discussions.

\section{REFERENCES} 1. G. Cimino, S. De Rosa, S. De Stefano and G. Sodano, Pure and Applied Chemi-
Stry,58, $375-386(1986)$.

2. G. Cimino, S. De Stefano, G. Scognamiglio, G. Sodano and E. Trivellone, Bull. Soc. Chim. Belg., 95, 783-800 (1986).

3. G. Cimino, A. Spinella and E. Trivellone, unpublished results.

4. J. C. Braekman, D. Daloze, P. Macedo de Abreu, C. Piccinni-Leopardi, G.Germain, M. Van Meerssche, Tetrahedron Letters, 23, 4277-4280 (1982).

5. J. C. Braekman, D. Daloze, N. Defay and D. Zimmerman, Bull. Soc. Chim.Belg., 93, $941-944(1984)$.

6. $\overline{\mathrm{M}}$.' Nakagawa and M. Endo, Tetrahedron Letters, 25, 3227-3228 (1984).

7. R. Sakai, T. Higa, C. W. Jefford and G. Bernardinelli, J. Am. Chern. Soc., $108,6404-6405$ (1986).

8. H. Nakamura, S. Deng, J. Kobayashi, Y. Ohizumi, Y. Tomotake, T. Matsuzaki and $Y$. Hirata, Tetrahedron Letters, 28, 621-624 (1987).

9. H. P. Hamlow, S. Okuda and N. Nakagawa, Tetrahedron Letters, 2553-2559(1964).

10. F. Bohlmann, Chem. Ber., 91, 2157-2167 (1958).

11. N. J. Leonard, J.A. Adamick, C. Djerassi and O. Halpern, J. Am. Chem. Soc 80, 4858-4862 (1958) and references therein.

12. $\bar{F}$.'J. Schmitz, K. H. Hollenbeak and D. C. Campbell, J. Org. Chem., 43, 3916-3922 (1978).

13. E. Quinoà and P. Crews, Tetrahedron Letters, 28, 2467-2468 (1987).

14. C. Cristophersen, in "The Alkaloids"A. Brossi, Ed., Academic Press, New York, 24, 25-111 (1985).

15. C. L. Liotta, H. P. Harris, M. MC Dermott, T. Gonzalez and K. Smith, Tetra.* hedron Letters, 28, 2417-2420 (1974). 